\title{
Psychological aspects of resentment and forgiveness
}

\author{
Mkrtchyan Tsovinar Lenvelovna \\ Chair of history and theory of psychology, Yerevan State Pedagogical University. University of a name of Khachatur Abovyan, Republic \\ of Armenia
}

\section{Email address:}

tsovinar.mkrtchyan@gmail.com, akhudaverdyan@mail.ru

\section{To cite this article:}

Mkrtchyan Tsovinar Lenvelovna. Psychological Aspects of Resentment and Forgiveness. Psychology and Behavioral Sciences. Vol. 3, No. 1, 2014, pp. 1-5. doi: 10.11648/j.pbs.20140301.11

\begin{abstract}
The phenomenon of offense and forgiveness are shown in the interpersonal relations in which two - the offender and the victim are involved. The method is under construction on a combination of a lecture, seminar and practical training. At students reconsideration of sensitivity is reflected in difficult cognitive processes in which the external and internal factors influencing knowledge of reality and an objectivication of created concepts are closely bound.
\end{abstract}

Keywords: Offense, Offender, Forgiveness, Victim, Self-Checking; Self-Understanding

\section{Introduction}

Among diverse negative experiences the special place is taken by offense. The offense is reflected in communication, in qualities of nature of the person [1], is shown in depressions, mistrust to each other and in uneasiness. The offense includes experience to the offender and pity to itself. Sensitivity as quality of the personality - tendency in everything to see offense, to start, untwist and endure a resentment, and also not to forgive the offender. Sensitivity should be referred to the emotional, dynamic lines of the personality created by the environment. Thinkers of different times addressed to consideration of such manysided phenomenon: Publy Sir, Lutsy Annya Seneca, Voltaire (François-Marie Arue), Pythagoras Samos, Demokkrit Abdersky, Alisher Navoi (Nizamadkdin Mir Alisher), Plutarch, Feognid (Teognid), Solon, William Shakespeare, Niccolo Machiavelli, Arthur Schopenhauer, Friedrich Nietzsche.

\section{Essence Forgiveness and Offence}

Forgiveness - the many-sided process requiring forces and energy and granting healing for offenses. J. Nort [2], the River Enrayt [3, 4] and E. Gassin [5] specify that forgiveness manifestation in the interpersonal relations in a general view can be determined as the decision: 1) to give up negative thoughts, emotions and behavioural manifestations concerning the individual who unfairly has offended you, 2) to encourage positive thoughts, behavioural manifestations and emotions concerning the same offender. We find understanding of forgiveness in researches of psychologists as personal sense [6], the moral act [7], healings [8], acceptances of another [9], as active overcoming of negative orientation in relation to the offender, and also developments in relation to the last positive orientation (to the River Enrayt, E.Gassin). The phenomenon of forgiveness is also a philosophy learning object $[2,10,11]$ and medicine $[12,13,14]$.

\section{About Training "Don't Take Offense"}

The problem of this research is reduced to need of studying of psychological aspects of interpersonal forgiveness on the basis of which there would be possible a creation of conditions for constructive interaction of the persons which have appeared in a situation of offense, the conflict, crisis of the interpersonal relations. We represent an author's technique and recommendations about search and expression of offenses and forgiveness. Factors and conditions of their overcoming are revealed connected with offense and sensitivity.

In work the example of a method of active training in educational process which will be approved with the principles of modern education is provided: the principle of managed transition from activities in an educational situation to activities in a life situation; the principle of managed transition from joint educational and informative activities to independent activities of pupils. The training 
has a theoretic-practical nature and gives the chance to reveal a phenomenon of offense and the importance of forgiveness in process of human communication.

The training is called "Don't take offense". The name is chosen with the purpose to concentrate attention of the listener at the exit from a problem. Being prevention of overcoming of sensitivity, the methodic's name at the same time is installation and generates in soul of the personality a question "how?" The methodic consists of two parts. The first part is provided in the form of dialogue (the psychologist - the student). In the second part the psychologist, generalizing and summarizing the facts received in the first part, formulates the main theoretical knowledge of a problem. As a distinctive sign extent of activization of students or nature of educational and informative activities is used. All methods of activization of informative activities belong to an active training method on lecture occupations also.

This training passed long approbation [15]. 417 people are researched: 298 women and 119 men - students of I and the II rates of the Yerevan state pedagogical university in from 18 to 28 years. We carried out a technique in the 2 nd and in the 3rd courses, at the lectures "psychology of family life" and "family relationship" to time lessons (during two meetings at different times of the day). During the first meeting we represent a training, at the second meeting we discuss results more deeply to understand this problem.

Addressing to the subject "Matrimonial Relations" "The psychology of family life" is aware, it is almost impossible to do without explanation of such important phenomena as offense and forgiveness. The interest of students shown directed by various questions this subject was the cause for representation of this technique. The technique gives the chance to rethink the relation and installation to this often meeting in life complex and inevitable problem. The solution of this problem very important, otherwise a problem not only won't be solved, and will amplify. We offer a certain technique which notes ways of prevention of a phenomenon of sensitivity.

The training can be carried out as in various social groups, and individually. This difficult mental condition gives the chance to help the person to rethink techniques. By means of again created positive installations to intensify self-checking and self-control processes [16, 17].

The technique can be carried out as in various social groups, and individually. Training purpose:

1. to help the person to rethink this difficult mental state

2. by means of again created positive installations to intensify self-checking and self-control processes.

Briefly we will provide content of an author's training.

\subsection{Training "Don't Take Offense"}

Psychologist (P) - Today we will analyse a state of mind which rather often meets at us in life - an offense phenomenon. First of all I will ask you to answer the following questions. Do you want we will carry out with you a training which is called " don't take offense".
The student (S) . Yes we want (raise hands). .

Students with great pleasure responded to it.

P . Psychologists speak. "don't take offense". Let those who willy-nilly ever offended the person will raise hands.

The student (S) - (raise hands).

Item - And now let those who was offended will raise hands.

S. - (raise hands).

P. - Judging by the raised hands, it is possible to assume that you someone offended and also you are offended by someone. You agree with such generalization?

S.- Yes.

P. - And now let those who considers himself sensitive and throughout life wished to change, tried to make it, will raise hands .

S. - (raise hands).

P. - Accept my condolences. You will be offended even more.

S. - (is surprised). But why?

P. - And here about it we will talk right at the end. Now let's answer the following questions. What do you understand as expression real life?

S. - Overcoming of difficulties, war, fight, a train of problems, etc. (if necessary the psychologist can prompt the answer).

P.-If life is war, fight, who its participants?

S.-Soldiers, fighters.

P.- The soldier, the fighter fights to win. If it wound, it will be able to continue fight?

S.- Depends on wound. If wound serious - that isn't present if a lung - that probably to it is possible to continue fight.

P. - It is difficult to wounded soldier to battle. Some wounded carry away in hospital from a battlefield. Sensitivity has the same nature.

"From a wedding cheerful from the house of that

Mosi leaves, is hard offended:

His saddened heart" boils.

Hovhannes Tumanyan (the Armenian writer)

We offer a new exit from a situation - "Don't take offense". But before we will talk about a state of mind in which you appear when you offend.

S. - (describe options): I happen to be suppressed, I cry, I am offended, etc.

P. - How do you try to leave this negative emotional condition?

S. - I tell about happened to friends, parents, etc.

P. - When you in detail tell all to your relatives and they actively empathize you, what you feel?

S. - I for some time calm down, but then when I remember or I happen upon the offender, again I endure the same feelings.

P. - In aspiration to be exempted from a burdensome emotional condition we start looking for an exit from the current situation. How you in that case arrived?

S. - I tried to ignore, then after long sufferings, finally, having analysed a situation, I aimed to sort out the relations 
with the offender.

\subsection{We Represent the Second Part of a Training}

P. - If we have no corresponding knowledge of this problem, we won't be able to understand what is created with us, in our environment and, eventually, we won't know how to overcome this problem.

Sensitivity is one of the most complex and widespread problems. In the explanatory dictionary [18] is given the following determination of sensitivity: "Grief, mental anguish". It is possible to offend by the word (oral, written), movement, a look, action, publicly or in absentia. This mental condition is accompanied by uneasiness, confusion, sufferings, a depression and can bring to the person the same sufferings, as well as the hardest illness. Usually it arises in the interpersonal relations, between offended and the offender. The offended person is similar to the victim which has got to a trap which long time can't be recovered, leave the deadlock. The victim, punishing itself, it is locked at home, doesn't talk, changes a conduct of life. It trying to sort out the relations, all the time mentally argues with the offender to be exempted from negative emotions, starts "being on the tramp", share the experiences with friends, neighbours, native. However any insignificant detail connected with the offender (a meeting, reminiscence, etc.), removes it from temporarily found balance.

It is necessary to consider and that circumstance that "victim" becomes not only offended, but also the offender as he too appears in an awkward provision: regrets for deeds (in certain cases) _ and this feeling, probably, can change his life, having turned it into heavy burden. Both parties spend the most part of the emotional and informative energy for suffering. The unique solution of a question - a frank showdown with the offender. However, first of all it is necessary to analyse incident. Sooner or later there comes the moment when the offended person starts understanding that this unpleasant case can change his life in a root. And at this moment it has an understanding of importance of forgiveness when the personality revaluates the views in relation to the offender that helps it to understand his behavior. There is "reforming" that promotes emergence of empathy. The forgiveness is the process requiring forces and energy and having positive impact on physical and mental health of the personality. The forgiveness is that "lifebuoy" [1] which doesn't allow "victim" to drown in a hatred and suffering whirlpool. From frank forgiveness win both the victim and the offender. The sincere world of the person is some kind of "garden" where can find a shelter both desired, and unwanted guests. With the unwanted guest offender, the person is irreconcilable, constantly mentally argues with it as yet he didn't forgive him and didn't release from "garden" of the soul with love and peace. Only by forgiveness it is possible to exempt the soul from sufferings. Otherwise the problem not only isn't solved, but also goes deep and the it is deeper, the it is more difficult to solve it.

\section{Steps of Process of Receiving Forgiveness}

Briefly we represent forgiveness process which was described by psychologist R. Enrayt [4]. The phase of understanding of a situation - at this stage takes place understanding of waste of emotional energy in an offense condition, fixed reflections about the insults addressed to him (comparison, the analysis, generalization), desire to be exempted from this freight. Decision making phase readiness for forgiveness. The action phase - the person (personality) shows empathy in relation to offended, starts regretting for deeds and recognizes the offense. The phase of results - at the last stage of people realizes importance of forgiveness - the caused offense can negatively affect further his life.

It should be noted that it is impossible to force the offended person to show condescension. It is necessary to promote first of all to understanding to them in what the essence of forgiveness consists.

The ratio of forgiveness and sensitivity can be various:

There are moments when at heart you forgive the person, but can't forget the offense addressed to you. Let's note that serious and deep offenses seldom drop out of consciousness. It is possible to remember, but to forgive. If, remembering incident or meeting the offender, the person has no sincere experiences, it is possible to tell that the person forgave. In an opposite case it witnesses that there were still the questions requiring a final explanation and the decision. What emotional experiences are we having when we are occurring with the offender. Fear, alarm, concern, trouble, anxiety. With whom we have such feelings? With enemy. And how to do? In such cases it is very important to work with ourselves. It is necessary to forgive, release and mentally to wish happiness and to tell. " I wish you happiness". and having repeated it periodically fear, concern, tension will pass.

There is a category of people at whom sensitivity is the integral line of their nature, inseparable part of their life. Researches showed that people who often take offense, constantly appear in similar situations. Life as though specially "offends" them. And it will last until they won't come to conclusion that so it is impossible to live further. While they won't make the decision not to take offense any more.

"Don't take offense" - why? :

$>$ Because don't want to be the "victim" which has got to a trap.

$>$ Don't want to spend excess emotional and learning energy.

$>$ Don't want to be vulnerable.

$>$ Don't want to deviate the purposes.

When the offended person wants to change, as he, and the relation of people around gradually changes. That fact isn't subject to doubt that in the interpersonal relations offenders, people who, using vulnerability of others rather often meet, intentionally offend those, thereby trying to eliminate "disturbing" from the way. In such a way they are easily exempted from the opponents. If the person isn't 
sensitive, difficult to attack, he timely solves the problems with the offender. "Having understood" it and without taking offense, achieves the object. From here conclusion: "don't take offense".

\section{Results and their Discussion}

We conducted research of psychological features of overcoming of offense and sensitivity among students of the Yerevan State Pedagogical University. The offense analysis, as negative emotional condition and sensitivity, as lines of the personality was carried out. The purpose of our research caused statement of the following tasks: to cover theoretical the basics of offense, as negative emotional condition and sensitivity, as property of the personality and conditions of their overcoming, and also to study offense and sensitivity manifestations at students 1 and 2 rates, to describe and characterize individually typical features of manifestation of offense and sensitivity.

Results of researches which were conducted for a number of years, allowed to come to a certain conclusion on this matter. Separate age groups of students (Tab. 1) were involved in research.

Table 1. Indicators of reconsideration of a problem of sensitivity in different age groups of examinees

\begin{tabular}{lll}
\hline & I rate resident instruction & I rate correspondence course \\
\hline Age of $18-22$ & $28,2 \% *\left(20^{* * / 71 * * *)}\right.$ & $43,75 \%(35 / 80)$ \\
women & $26,1 \%(12 / 46)$ & $40,99 \%(25 / 61)$ \\
men & $32 \%(8 / 25)$ & $52,7 \%(10 / 19)$ \\
Age of $23-27$ & $71,5 \%(10 / 14)$ & $54,3 \%(19 / 35)$ \\
women & $77,8 \%(7 / 9)$ & $52 \%(13 / 25)$ \\
men & $60 \%(3 / 5)$ & $60 \%(6 / 10)$ \\
& II rate resident instruction & II rate correspondence course \\
Age of $19-23$ & $31,1 \%(23 / 74)$ & $44,9 \%(39 / 87)$ \\
women & $32 \%(16 / 50)$ & $45,6 \%(31 / 68)$ \\
men & $29,2 \%(7 / 24)$ & $42,2 \%(8 / 19)$ \\
Age of $24-28$ & $58,4 \%(7 / 12)$ & $54,5 \%(24 / 44)$ \\
women & $60 \%(6 / 10)$ & $55,2 \%(16 / 29)$ \\
men & $50 \%(1 / 2)$ & $53,4 \%(8 / 15)$ \\
\hline
\end{tabular}

* Percentage indicators of reconsideration of sensitivity among group of students at the age of 18-22 years.

** The students having positive survey results.

$* * *$ Number of examinees.

According to this table, we can assume that certain dynamics between age groups in reconsideration of the offered problem is observed. Students of advanced ages perceived essence and a role of prevention of a problem in their life more accurately. According to these data undergraduates more ripened approached to discussion and they are ready to changes in their life.

In all groups carrying out a methodic came to an end with interviews and sincere recognitions in a written or oral form, that also proved importance of this psychological problem. The experiment made by us allows to speak about the following results - the students are more senior, the problem understanding is higher. The data obtained in our research allow to reveal also distinctions among men and women. Big in comparison with men the emotionality of women proves to be true in this research.

\subsection{Conclusion}

Forgiveness is an essential part of strong, healthy relationships. Christian beliefs teach that nobody is exempt from forgiveness; we should forgive all wrongs that have been done to us, regardless of their severity. Once thought to be exclusively a religious doctrine, the notion of forgiveness has rapidly moved beyond religious borders into mainstream society. One definition of forgiveness is the ability to release the mind and the heart from all past hurts and failures, all sense of guilt and loss. Forgiveness enables us to overcome anger and feelings of resentment or a desire to punish or get even with someone who has crossed us.

My acknoledgements to my dear father Lenvel Mkrtchyan for financing of this scientific work.

\section{References}

[1] L.B. Schneider, "Phsycology of the family relations": Lecture. Moscow: EKSMO-Press. 2000.

[2] J. North, "Wrongdoing and forgiveness", Philosophy 1987, № 42, pp. 499-508.

[3] R. Enright, "The Human Development Study Group. The moral development of forgiveness", in Handbook of Moral Behavior and Development, W. Kurtines and J. Gewirtz Eds. Hillsdale, NJ: Erlbaum, 1991, pp. 123-152.

[4] P. Enrayt, "Spiritual development of forgiveness". Moscow: publishing house Academy, 1991. 
[5] E.A. Gassin, "Phsycology of forgiveness", Psychology Questions, 1999, N 4, pp. 93-104.

[6] V. Frankl, "The Doctor and the soul'. St. Petersburg: Juventa, 1997.

[7] A.A. Rodionova, "Satisfaction of moral requirement for forgiveness as condition of personal growth: on the example of the family relations". Doctoral dissertation. Tambov. 2007.

[8] E. Fromm, "For the Love of Life". New York, 1986.

[9] Yu.M. Orlov, “Offense.Fault”, 5th prod. M. Slayding, 2004.

[10] R.U. Richardson, "Forces of family bonds". St. Petersburg, 1994.

[11] L.B. Smedes, "Forgive and Forget Healing the Hurts We Don't Deserve". San Francisco: Harper \& Row, 1944.

[12] D. J. Stein, S. Seedat, D.Kaminer, H.Moomal, A. Herman, J. Sonnega, et al., "The impact of the truth and reconciliation process on psychological distress and forgiveness in South Africa", Social Psychiatry and Psychiatric Epidemology 2008, vol. 43, pp. 462-468.

[13] D. Kaminer, D.J. Stein, I. Mbanga, and N. Zungu-Dirwayi,
"The Truth and Reconciliation Commission in South Africa: relation to psychiatric status and forgiveness among survivors of human rights abuses", Br J Psychiatry, 2001, vol. 178 , pp. 373-377.

[14] K.A. Lawler, J.W. Younger, R.L. Piferi, E.Billington, R. Jobe, K. Edmondson, et al., 'A change of heart: Cardiovascular correlates of forgiveness in response to interpersonal conflict", Journal of Behavioral Medicine 2003, vol. 26(5), 373-393.

[15] Ts.L. Mkrtchyan, "Consequences and Ways of Resentment Prevention", Collection of Materials, 53rd Anniversary Scientific Conference of the Faculty, Graduate Students, Competitors and Scientists (November, 7-9, 2007). Yerevan: "Pedagog" Publishing House, 2007, pp. 112-115.

[16] Ts.L. Mkrtchyan, "The Role of word reconsideration in the course of personality", Almanac of modern science and education, 2013, No. 8 (75), pp. 111-115.

[17] G. Nikiforov, "Self-checking S G. S. Nikiforov", Leningrad: Publishing House of the Leningrad University, 1989.

[18] E.B. Agayan, "Tolkovy dictionary of modern Armenian language. In two volumes". Yerevan: Ayastan's publishing house, 1976. 